\title{
A study of the impact of strategic thinking on the performance of Mashhad municipal managers
}

\author{
Mahdi Mahdavian ${ }^{a^{*}}$, Vahid Reza Mirabi ${ }^{\mathrm{b}}$ and Farideh Haghshenas ${ }^{\mathrm{b}}$
}

${ }^{a}$ M.A. Student in Executive Management, Electronic Branch, the Islamic Azad University of Tehran, Iran

${ }^{b}$ Faculty Member, Central Branch, the Islamic Azad University of Tehran, Iran

\section{CH R O I C LE A B S T RACT}

Article history:

Received July 28, 2013

Received in revised format

20 November 2013

Accepted 14 January 2014

Available online

February 222014

Keywords:

Strategy

Strategic thinking

Performance

Municipality

\section{Introduction}

Nowadays, many organizations are increasingly facing complicated problems and need for proper thinking to offer modern solutions. In many cases, the attempts made by managers and officials could temporarily overcome the problems and sometimes leading to more serious problems and even exacerbating the previous ones. One of the problems is associated with the lack of strategic thinking among top managers. Inclination towards strategic thinking can create a vital function at two levels i.e. individual and organizational leading to form the basis of a steady competitive advantage. In fact, strategic thinking at the two levels of individual and organizational may create a foresight and comprehensiveness, which not only improves employees' understanding of work environments and organizations, but also it can pave the way for more connections and interactions between managers

\footnotetext{
*Corresponding author.

E-mail addresses: mahdavian.mahdi@gmail.com (M. Mahdavian)

\begin{abstract}
This examines the impact of strategic thinking on the performance of Mashhad municipal mangers. Strategic thinking as one of the ways of thinking has a crucial place in the modern world and plays essential role in major issues at different organizational levels including increase our performance using strategic thinking. Organizations are being involved in competitive and chaotic situations; therefore, they need managers with strategic thinking. Nevertheless, there are some organizations throughout the world managing their business activities in increasingly difficult situations with highly developed duties. Therefore, they need strategic thinkers to cope up with the mentioned problems and Mashhad Municipality is no exception to this policy because it has a special place among all aspects of metropolitan
districts. Thus, this study has attempted to explain of the impact of strategic thinking on the performance of Mashhad municipal managers. The results obtained from the study show that strategic thinking had an acceptable level among municipal managers of Mashhad City and all factors of strategic thinking improved their performance.
\end{abstract}

(C) 2014 Growing Science Ltd. All rights reserved. 
and employees as well as utilizing skills and creativities of employees at organizational levels. Municipalities manage their own work environments due to increasingly complicated business activities throughout the world. Nowadays, decision-making power has given to the municipalities in different ways building high expectations of the public requiring urban planning and systematic management to reach their needs. The increase in dynamics and mobility of capital and related conditions such as environmental regulations as well as creating new markets specify that municipalities could never resist joining the framework of global performance.

\section{Discussing the Issue}

Many firms are being involved in competitive and chaotic circumstance such that they require to be equipped with the tools of strategic thinking, which is essential to develop and to survive in such chaotic events and it plays special role in the modern world. In addition, strategic thinking plays essential role in various issues at different firm levels including individual decision-making and planning. We can expand our horizons and take the opportunity to increase our performance based on strategic thinking. Besides, governmental organizations and private enterprises require strategic thinking more than before because of increase competition. There are many cases where managers and officials could temporarily overcome the challenges and sometimes face with some serious problems and even exacerbating the previous ones (Rabiee et al., 2011). In addition, the inclination towards privatization and global business has been increased in Iran because of efficient tools of strategic thinking in line with global trend. Therefore, the improvement of strategic thinking among managers as an important factor in effectiveness of strategic thinking process needs more consideration. Hence, municipalities facing complicated problems in managing their work environments because of the new development of organizational responsibilities are in desperate need of strategic thinking for their managers (Shahamatnejad, 2012). Therefore, this paper aims at examining the effect of strategic thinking on municipal managers in Mashhad as an important metropolis in Iran.

\section{The Necessity of Research}

The general outline of this study shows that there were many problems due to the lack of strategic planning in Mashhad metropolis with an area of 300 square kilometers and with a population of about 3 million. Such problems cannot be solved through master plans or temporary solutions; on the contrary, they just increase the costs of Mashhad Municipality resulting in widespread dissatisfaction expressed by people and pilgrims (Husseini Raad, 2011). The environment is increasingly being destroyed and people's expectations have been raised so that they were demanding urban planning and systematic management available to meet their requirements. In addition, municipalities' financial resources are increasingly being constrained. Thus, the municipal managers who have handled their organizations in a chaotic situation and their duties have been developed in various aspects are in need of flexible and innovative approach within the framework of strategic thinking (Shahamatnejad, 2012). Therefore, the ability to think strategically needs substantial attention as a supplement for strategic planning to develop effectiveness of strategic management among Mashhad municipal managers. As top managers play crucial role in managing an unstable environment, this paper has been aimed to evaluate the effect of strategic thinking on the performance of Mashhad municipal managers to prove its evidence, overcome managers' problems and limitations as well as improve their abilities.

\section{Research Purposes}

\section{Primary Purposes}

1. Identifying desirability level of strategic thinking factors among municipal managers,

2. Identifying the impact of strategic thinking on the performance of municipal managers. 
Secondary Purposes

1. Identifying and evaluating effective factors of strategic thinking in desirability level of managers' way of thinking,

2. Identifying and evaluating effective factors of strategic thinking in improving the performance of managers,

3. Determining the level of importance and prioritizing the level of desirability of strategic thinking factors among municipal managers and the relevant impacts on their performance.

\section{The Proposed Hypotheses}

\section{Primary Hypotheses}

1. Strategic thinking and its dimensions achieved a desirable level among municipal managers.

2. Strategic thinking has major impacts on the performance of municipal managers.

\section{Secondary Hypotheses}

1. Conceptual thinking has major impacts on the performance of municipal managers.

2. Systematic approach has major impacts on the performance of municipal managers.

3 . The process of foresight has major impacts on the performance of municipal managers.

4. Opportunism has major impacts on the performance of municipal managers.

5. Cognition has major impacts on the performance of municipal managers.

6. Transformational leadership has major impacts on the performance of municipal managers.

\section{Theoretical Model of the Research}

Theoretical model is considered a starting point for conducting research so that it determines the considered variables defined in the research. In other words, one can claim that the theoretical model is the very conceptual or mental model as a tool to analyze a strategy in order to begin and carrying out the research as expected, it can initially identify the relevant factors and then prioritize them in order of importance.

\begin{tabular}{|c|c|}
\hline & Performance \\
\hline & Work Quality \\
\hline & Planning \\
\hline Strategic Thinking & Observing the criteria and Instructions \\
\hline Conceptual Thinking & Performing the Tasks on time \\
\hline Systematic Approach & Having Knowledge, Expertise and Skill \\
\hline Foresight & Utilizing the Resources and Information \\
\hline Opportunism & Diligence in Learning and Gaining Experience \\
\hline Cognition & Creativity and Initiative \\
\hline Transformational Leadership & Teamwork Approach \\
\hline & Collaboration \\
\hline & Responsibility \\
\hline & Performing the assigned Duties \\
\hline
\end{tabular}

Fig.1. Dimensions of Strategic Thinking (Goldman, 2005; Ja'faryani, 2011; Rezvanpour, 2012)

There is no general agreement about the meaning of strategic thinking in the literature of strategic management. Some authors have used the concept of strategic thinking for other perceptions such as strategic planning and management. For instance, Wilson states: "Attempt to improve organizational affairs changed the basis of strategic planning so that we should regard it as strategic management or thinking" (Sarhangi, 2011). There are several issues for this definition as follows,

- Strategic thinking is associated with a creative and divergent process and planned by the leaders of organizations and their prospect. This process needs managerial thought far beyond daily operations in line with long-term strategic goals for business (Heracleous, 1998). 
- Strategic thinking consists of several activates such as collecting information, analyzing and exchanging ideas about prevailing views within an organization as well as answering key questions about organizational portfolios (Early, 2006).

- Strategic thinking is to detect reliable strategies or business models leading to construct values for the clients (Abraham, 2005).

- Strategic thinking is a lengthy process and its objective is to resolve ambiguity and signify a complicated environment (Bonn, 2005).

- Strategic thinking is the basis for creating new strategies to change competition rules as well as offering different prospect (Liedtka, 1998).

- Strategic thinking is considered a top managerial activity and its goal is to discover new and creative strategies to rewrite competition rules and also create a future potential that is totally different from the current form (Goldman, 2007).

- Strategic thinking is to identify the features of competitions as well as present invisible opportunities (Ghafarian \& Ahmadi, 2011).

\subsection{Basic components of strategic thinking}

\section{Conceptual Thinking}

Conceptual thinking is the capability to understand a situation or problem by detecting the models and considering major issues. In addition, conceptual thinking includes integrated issues and factors within a conceptual framework. Conceptual thinking covers the widespread use of experiences, creativities, deductive reasoning and intuitive process leading to find potential solutions and viable options (Goldman, 2005, 2007).

\section{Systematic Approach}

Systematic approach is considered a social approach, which uses systematic theories for generating desirable results or remarkable transformations. Such way of thinking has a unique approach to solve the problems in which certain issues are regarded as a part of overall structures. The framework of systematic approach supports the idea that different components of a system work separately when the systems are out of connection. The only way to understand the problems is to emphasize the importance of identifying all the components as a whole. Therefore, systematic approach offers that systems should be defined through a holistic approach (Ja'faryani, 2011).

According to Liedtka, a strategic thinker must initially have a mental model in his/her mind and then fully understand the relationship among its components. The process of strategy is a holistic and integrated approach although there are various activities among its components (Ghafarian \& Kiani, 2011).

\section{Opportunism}

In strategic thinking, managers must embrace new ideas all the time. This process can develop the spaces for strategic options and provide access to effective strategies as well. In strategic thinking, discovering and utilizing opportunities is regarded as the basic principle. The nature of this concept is to embrace new experiences in order to utilize strategic options in business environment (Goldman, 2005).

\section{Foresight}

Foresight can be summarized in three Ps and one W. The three Ps include Possible, Probable and Preferable future events and W refers to Wild Card. In addition to W, characters are some events with lower probabilities but they may happen. Management of a risky circumstance is the core of foresight. Many managers see themselves as the victim of environmental forces out of their control. They feel that they are not able to control their clients, markets, rivals and rules. Thus, they try to be 
more responsive rather than anticipate the demands. Foresight or futuristic leadership tries to shape a better future by identifying particular circumstances. Foresight is not the process of predictions or anticipation of particular events, but it is a systematic process of future plans in order to create reasonable expectations to identify opportunities and threats faced by organizations so that they can take special measures to provide desirable results (Ja'faryani, 2011).

\section{Cognition}

Cognition is a process achieved through understanding, logic and intuition. There are several ways to achieve cognition. One of them is to make a distinction between right and left hemispheres' activities. Additionally, it is clear that senior managers allocate three-fourth of their time to plans while middle managers spend two-third of their time at present. Therefore, senior managers try to play tactical role (Arayesh \& Golmohammadi, 2011). According to Mintzberg (1998), strategic leaders are mapdrawers and tactical managers execute their plans. In fact, strategic leaders try to predict the future through visualization (Mintzberg, 1998).

\section{Transformational Leadership}

Bronze (1987) who developed the concept of transformational leadership, classified executive managers into two groups i.e. actors (managers) and change-makers (leaders). Managers are basically associated with their organizations by distributing the required resources while leaders deal with some issues such as identifying and satisfying the needs and demands of their followers. Bronze did not regard the latter as a series of particular behaviors, but he considered it a process to raise morale and motivation among leaders and followers (Ja'faryani, 2011). Avolio and Bass (2004) defined transformational leadership as a process to influence main priorities reflected by subordinates and colleagues so that they can actively analyze their own concepts and challenge the leadership.

Bronze and Selznick were the pioneers of transformational leadership in 1970s. They showed that managers understand their followers' needs and determined organizational purposes according to their demands. As Bass stated, when the subordinates develop their organizations internally and supervisors mange them externally, transformational leadership can be achieved. Subsequently, transformational leaders create competence, insight, respect and trustworthiness (Ja'faryani, 2011).

\section{Performance}

Performance is to accomplish the duties determined by an organization for human forces. In the past few years, performance was referred to the duties defined within the scope of personnel's activities and indicated that how an employee performed his/her duties. "Performance" is misinterpreted as "attempt" while performance must be measured based on the results of activities (Byars \& Rue, 2008). Scientific definition of performance is total behaviors relating to occupations and according to this definition, the concept of performance is far beyond the scope of utilization (Griffin \& Moorhead, 2010).

\section{Occupational Performance}

Performance is a limit for employees to satisfy their occupational requirements (Gerhart \& Milkovich, 1990). In a more formal definition, occupational performance is referred to the quality and quantity of duties performed by an individual or group. Occupational performance is the infrastructure of utilization and it must be useful to achieve organizational goals (Shermhorn, 2002). According to Bayer Varro, performance of people can be resulted from the mutual relationships as follows: 
(a) Attempt: resulting from excitation and referring to the amount of energy (physical or mental) used by an individual to perform his / her duties.

(b) Abilities: individual characteristics used by an individual to perform his / her tasks.

(c) Perceptions of Role: referring to courses followed by individuals diligently to achieve their occupational goals (Byars \& Rue, 2008).

\section{Municipality}

Municipality is an area in which a city council has political authority to offer local and state services to the public. The services include sewage system services, combating crime and fire services (O'sullivan, 2007). Based on a specific definition, municipality is a public, non-governmental and independent enterprise established in cities according to the law and it is responsible for local affairs and offering services to citizen. According to Article 3 of municipal regulations, municipality has an independent legal entity (Kamyar, 2011).

\section{Research Method and Data Analysis}

Considering the proposed questions and issues, the present study follows functional method and its data was collected through a measurable approach but analytically uses descriptive-correlational method. Descriptive and inferential statistics are to analyze the data. In descriptive statistics, frequency distribution tables, central indexes and standard deviation are used. In addition, the relevant diagrams will be drawn. In inferential statistics, considering the suggested hypotheses, Kolmogorov-Smirnov Test was used for determining the normality of variables and the singlesample T Test, Regression Test and Structural Equations Modeling (SEM) were used for providing the hypothesis test. Additionally, SPSS software and LISREL were used for analyzing the data.

\section{Population and Sample}

This study received different comments from experienced experts and professionals as the subjects of this experiment; thus, the importance of their opinions can be increased. Considering the abovementioned fact, as it is impossible to consider the theme of this study without evaluating scientific, theoretical, experimental and practical principles, statistical population of this research includes all the senior managers of Mashhad Municipality i.e. 90 people $(\mathrm{N}=90)$; therefore, statistical samples equals statistical population due to the limited number of the subjects.

\section{Research Tool}

In this study, three kinds of standard questionnaires were used as follows: (1) desirability of strategic thinking level among managers; (2) the impact of strategic thinking on the performance of managers; and (3) considering the performance level among managers. It is necessary to say that the answers were based on 5-point Likert Scale Options for each questionnaire.

\section{Reliability}

As Cronbach's Alpha is usually an appropriate index for measuring the reliability; therefore, the reliability of the questionnaires of this research was measured through Cronbach's Alpha. The reliability of research tool relating to strategic thinking questionnaire was 0.886 , the value relating to the impact of strategic thinking on the performance of managers questionnaire was 0.828 and the value relating to managers' performance was 0.883 . Thus, the reliability was approved due to the appropriate Alpha Coefficients (higher than 70\%). 


\section{Research Findings}

Statistical population of this study includes 85 males $(94.4 \%)$ and 5 females (5.6\%). The age range of 56 subjects is between 30 and $40(62.2 \%)$ and 28 of them are between 40 and $50(31.1 \%)$ and 6 of them are between 50 and $60(6.7 \%)$. Educational levels of the subjects are as follows: 1 of them got college diploma (1.1\%), 25 of them got B.A. (27.8\%), 59 of them got M.A. (65.6\%) and 5 of them got doctorate (5.6\%). Majors: 11 of them; management (37.8\%), 11 of them; architecture (12.2\%), 4 of them; economics, 24 of them; engineering (26.7\%) and 17 of them; other majors (18.9\%). Their work experience: 6 of them; 1-5 years (17.8\%), 4 of them; 5-10 years (44.4\%), 20 of them; 10-15 years $(22.2 \%)$ and 14 of them; more than 20 years (15.6\%). Managerial experience: 16 of them; $1-5$ years $(17.8 \%), 38$ of them; $5-10$ years $(42.2 \%), 22$ of them; $10-15$ years $(24.4 \%)$ and 5 of them more than 20 years $(5.6 \%)$.

Primary Hypothesis (1): Strategic thinking and its dimensions achieved a desirable level among municipal managers.

Considering that the variable of strategic thinking and its dimensions include conceptual thinking, systematic approach and the cognition has a normal distribution; thus, the single-sample $\mathrm{T}$ Test was used for explaining the hypothesis given in Table 1 as follows,

\section{Table 1}

The Results of Single-Sample T Test; the Levels of Strategic Thinking, Conceptual Thinking, Systematic Approach and Cognition Variables

\begin{tabular}{ccccc}
\hline Factor & mean $\pm \mathrm{sd}$ & Statistic T & Degree of Freedom & Meaningful Level \\
\hline Strategic Thinking & $4.058 \pm 0.310$ & 25.102 & 89 & 0.0001 \\
Conceptual Thinking & $3.873 \pm 0.463$ & 17.433 & 89 & 0.0001 \\
Systematic Approach & $4.216 \pm 0.435$ & 16.473 & 89 & 0.0001 \\
Cognition & $4.04 \pm 0.324$ & 25.579 & 89 & 0.0001 \\
\hline
\end{tabular}

As indicated in the above-mentioned table, the meaningful levels of the levels of strategic thinking, conceptual thinking, systematic approach and cognition variables are less than 0.05 ; thus, $\alpha=0.05$ and we refuse zero hypothesis and accept the opposite hypothesis i.e. strategic thinking, conceptual thinking, systematic approach and cognition variables have appropriate levels. In addition, considering that foresight, opportunism and transformational leadership variables have not normal distributions; non-parametric single-sample test was used for explaining the hypothesis (Table 2).

\section{Table 2}

The Results of Single-Sample T Test; the Levels of Foresight, Opportunism and Transformational Leadership Variable

\begin{tabular}{cccc}
\hline Factor & mean \pm sd & Median & Meaningful Level \\
\hline foresight & $4.062 \pm 0.430$ & 4 & 0.0001 \\
opportunism & $4.053 \pm 0.418$ & 4 & 0.0001 \\
transformational leadership & $4.137 \pm 0.401$ & 4.16 & 0.0001 \\
\hline
\end{tabular}

As indicated in the above-mentioned table, the meaningful levels of the levels of foresight, opportunism and transformational leadership variables are less than 0.05 ; thus, $\alpha=0.05$ and we refuse zero hypothesis and accept the opposite hypothesis i.e. foresight, opportunism, and transformational leadership variables have appropriate levels.

Primary Hypothesis (2): Strategic thinking has major impacts on the performance of municipal managers. 
Considering that the variable of strategic thinking and its impact on the performance of managers has a normal distribution; thus, the single-sample $\mathrm{T}$ Test and Regression Test were used for explaining the hypothesis.

Table 3

The Results of Single-Sample T Test; the Levels of Strategic Thinking Impact on Managers' Performance

\begin{tabular}{lcccc}
\hline Factor & mean \pm sd & Statistic $\mathrm{T}$ & Degree of Freedom & Meaningful Level \\
\hline $\begin{array}{l}\text { The impact of strategic thinking on } \\
\text { managers' performance }\end{array}$ & $4.058 \pm 0.301$ & 33.354 & 89 & 0.0001 \\
\hline
\end{tabular}

As indicated in Table 3, the meaningful levels of the level of strategic thinking impact on managers' performance variables is less than 0.05 ; thus, $\alpha=0.05$ and we refuse zero hypothesis and accept the opposite hypothesis i.e. strategic thinking impact on managers' performance has appropriate levels. For measuring the effect of strategic thinking on managers' performance, we initially consider Durbin-Watson Statistic Test and Coefficient of Determination using Regression Test. DurbinWatson Statistic equals 1.992; therefore, regressive model is appropriate and the remainders are independent values. The value of $\mathrm{R}^{2}$ equals 0.888 and it considered an appropriate value. The results of regression table and statistical indexes indicate that strategic thinking has a positive impact on the performance of managers $(\mathrm{p}=0.0001$ and $\mathrm{F}=305.657)$.

Secondary Hypothesis (1): Conceptual thinking has major impacts on the performance of municipal managers.

For measuring the effect of conceptual thinking on managers' performance, we initially consider Durbin-Watson Statistic Test and Coefficient of Determination using Regression Test. DurbinWatson Statistic equals 1.716; therefore, regressive model is appropriate and the remainders are independent values. The value of $\mathrm{R}^{2}$ equals 0.517 and it considered an appropriate value. The results of regression table and statistical indexes indicate that conceptual thinking has a positive impact on the performance of managers $(\mathrm{p}=0.0001$ and $\mathrm{F}=94.281)$.

Secondary Hypothesis (2): Systematic approach has major impacts on the performance of municipal managers.

For measuring the effect of systematic approach on managers' performance, we initially consider Durbin-Watson Statistic Test and Coefficient of Determination using Regression Test. DurbinWatson Statistic equals 2.031; therefore, regressive model is appropriate and the remainders are independent values. The value of $\mathrm{R}^{2}$ equals 0.655 and it considered an appropriate value. The results of regression table and statistical indexes indicate that systematic approach has a positive impact on the performance of managers $(\mathrm{p}=0.0001$ and $\mathrm{F}=167.3)$.

Secondary Hypothesis (3): The process of foresight has major impacts on the performance of municipal managers.

For measuring the effect of foresight on managers' performance, we initially consider Durbin-Watson Statistic Test and Coefficient of Determination using Regression Test. Durbin-Watson Statistic equals 1.919; therefore, regressive model is appropriate and the remainders are independent values. The value of $\mathrm{R}^{2}$ equals 0.493 and it considered an appropriate value. The results of regression table and statistical indexes indicate that foresight has a positive impact on the performance of managers $(\mathrm{p}=$ 0.0001 and $\mathrm{F}=85.613$ ). 
Secondary Hypothesis (4): Opportunism has major impacts on the performance of municipal managers.

For measuring the effect of opportunism on managers' performance, we initially consider DurbinWatson Statistic Test and Coefficient of Determination using Regression Test. Durbin-Watson Statistic equals 1.88; therefore, regressive model is appropriate and the remainders are independent values. The value of $\mathrm{R}^{2}$ equals 0.355 and it considered an appropriate value. The results of regression table and statistical indexes indicate that opportunism has a positive impact on the performance of managers $(p=0.0001$ and $F=48.481)$.

Secondary Hypothesis (5): Cognition has major impacts on the performance of municipal managers.

For measuring the effect of cognition on managers' performance, we initially consider DurbinWatson Statistic Test and Coefficient of Determination using Regression Test. Durbin-Watson Statistic equals 1.758; therefore, regressive model is appropriate and the remainders are independent values. The value of $\mathrm{R}^{2}$ equals 0.698 and it considered an appropriate value. The results of regression table and statistical indexes indicate that cognition has a positive impact on the performance of managers $(p=0.0001$ and $F=203.661)$.

Secondary Hypothesis (6): Transformational leadership has major impacts on the performance of municipal managers.

For measuring the effect of transformational leadership on managers' performance, we initially consider Durbin-Watson Statistic Test and Coefficient of Determination using Regression Test. Durbin-Watson Statistic equals 1.1.603; therefore, regressive model is appropriate and the remainders are independent values. The value of $\mathrm{R}^{2}$ equals 0.558 and it considered an appropriate value. The results of regression table and statistical indexes indicate that transformational leadership has a positive impact on the performance of managers $(p=0.0001$ and $F=13.32)$.

Now, considering the results of secondary hypotheses, we can fit a model among the dimensions of strategic thinking impacts on Mashhad municipal managers.

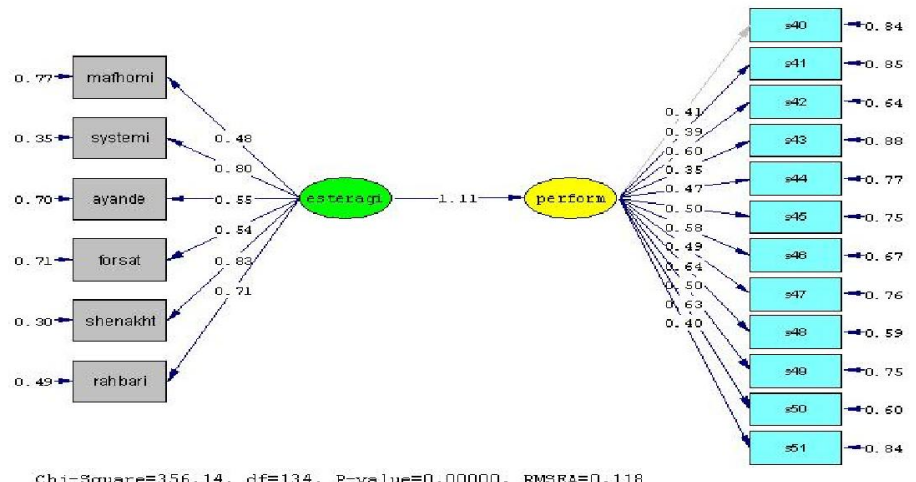

Fig. 2. The impact of strategic thinking dimensions on the performance of Mashhad municipal managers

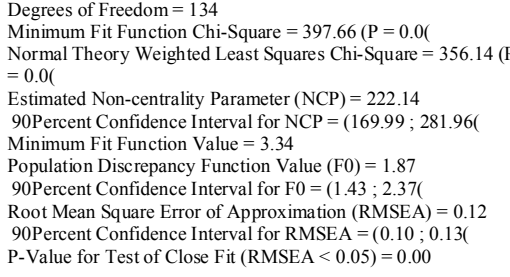

Expected Cross-Validation Index $(\mathrm{ECVI})=3.61$ ECVI for Saturated Model $=2.87$

ECVI for Independence Model $=18.92$

Chi-Square for Independence Model with 153 Degrees of

Freedom $=2215.63$

Independence $\mathrm{AIC}=2251.63$

Model AIC $=430.14$

Saturated $\mathrm{AIC}=342.00$

Independence $\mathrm{CAIC}=2319.80$

Model CAIC $=570.28$

Saturated CAIC $=989.66$
Normed Fit Index $(\mathrm{NFI})=0.82$

Non-Normed Fit Index $(\mathrm{NNFI})=0.85$
Parsimony Normed Fit Index $(\mathrm{PNFI})=0.72$ Comparative Fit Index $(\mathrm{CFI})=0.87$

Incremental Fit Index $(\mathrm{IFI})=0.87$

Relative Fit Index $(\mathrm{RFI})=0.80$

Critical $\mathrm{N}(\mathrm{CN})=53.37$

Root Mean Square Residual $(\mathrm{RMR})=0.087$

Standardized RMR $=0.087$

Goodness of Fit Index $(\mathrm{GFI})=0.75$

Adjusted Goodness of Fit Index (AGFI) $=0.68$

Parsimony Goodness of Fit Index (PGFI) $=0.59$ 
According to Table 3, standard coefficient is more than 0.3 in all cases so that none of them illustrated with red color; therefore, the dimensions of strategic thinking has a positive impact on Mashhad municipal managers. In addition, the general results obtained from this study indicate that the value of $\mathrm{K}^{2}$ equals 356.14 and its degree of freedom is 134 . Additionally, the ratio of $\mathrm{K}^{2}$ to degree of freedom is 2.65 i.e. less than 3. In addition, there is a meaningful level equals 0.0001 and the value of RMSEA Static is 0.118 that is less than 0.05. Thus, the considered model is acceptable. Other results are as follows:

\section{Discussion and Conclusion}

Based on the results and hypotheses offered in this research, we can see that primary hypotheses indicate an appropriate level for strategic thinking and its direct effect on the performance of Mashhad municipal managers has been approved. Therefore, we can conclude that personnel with strategic thinking must be employed to improve the performance of an organization. In addition, such strong performance thanks to strategic thinking can fulfill the expectations of pioneers such as Liedtka, Mintzberg, Handford, Heracleous and so on. Of course, we have to do our best to develop, improve and promote the level of strategic thinking. Therefore, there are some suggestions as follows:

(1) It is necessary to encourage initiative and innovations among employees and managers to create an organizational environment in which each individual is motivated to create innovation in line with strategic thinking. Institutionalizing innovation must be rooted in personnel's fondness and interest. In addition, decision-making must be given to individuals in order to find creative and unique solutions for gaining the advantage of competition. In line with the mentioned goals, thoughtful persons should take prominent positions. In addition, the followings are recommended to stimulate initiative and innovation among the members of an organization:

- Adjusting the assigned duties to their skills, interests and abilities

- Give them full independence to perform their tasks freely

- Rewarding them for their initiatives

- Providing their required resources

- Job Rotation

(2) It is worth providing a mental model for municipal managers as strategic thinkers in order to understand all mutual relationships within an organization. Such thinkers must adapt to interpersonal relationships in different parts and integrate all parts. In addition, experts and managers must quit their self-centered viewpoints and pay more attention to separate components of the organization not to the whole of it. The followings are essential to promote a holistic or systematic approach:

- Focusing on the role of internal factors in achieving organizational purposes

- Focusing on the role of external factors in achieving organizational purposes

- Focusing on work environment as a component of the whole business (Mashhad Municipality)

- Embracing clients' notions (internal and external relationship) in decision-making process

- Counting opportunities and threats

- Focusing on work environment in order to create values

(3) Providing a forum for discussion and debate is an appropriate measure for the members to exchange their ideas in line with strategic thinking.

(4) Scenario planning considered a useful technique to create new approaches or strategic options. Having different scenarios for the future enables senior managers to use several options when facing serious situations. Of course, such process requires skilled people to teach other members in the form 
of a group to create a "mental storm" of different options for the foreseeable future. Another advantage can be gained through scenario planning is to challenge mental images of managers and decision-makers who develop strategic thinking.

(5) Another factor that improves strategic thinking within an organization is managerial style because senior managers must share their ideas with the subordinates and middle managers to involve them in decision-making process; thus, senior managers require a collaborative style to manage new approaches in order to promote strategic thinking within their organizations instead of adopting bossy approaches.

(6) The award scheme is an appropriate method to encourage managers and employees to think strategically because this process can motivate them to collaborate. Providing such award scheme can influence the members leading to important results in managerial decisions and strategies. In addition, creative and capable workers must be supported by senior managers.

Finally, the following recommendations can be implemented in line with strategic thinking:

- Considering the effects of environmental changes on the activities of subordinate groups.

- Creating positive attitude towards changes as a tool to discover new opportunities

- Creating values and opportunities for the citizens

- Visibility of embracing employees' attitudes

- Optimizing organizational performance (technology, human resources, physical ability and so on)

- Creating research teams and exploiting the results of their research within the organizations

\section{References}

Abraham, S. (2005). Stretching strategic thinking. Strategy \& leadership, 33(5), 5-12.

Anthony, R.D. (1965). Planning and control system: A framework for analysis. Division of Research, Harvard Business School, Boston, 24.

Arayesh, B., \& Golmohammadi, E. (2011). Strategic thinking, the necessity of present managers of Iran. International Proceedings of Economics Development \& Research, 11, 3.

Avolio, B., \& Bass, B. (2004). Multifactor Leadership Questionnaire: Sampler set: Manual, forms and scoring key. Distributed by Mind Garden, Inc. Retrieved on January, 14, 2007.

Bonn, I. (2005). Improving strategic thinking: a multilevel approach. Leadership \& Organization Development Journal, 26(5), 336-354.

Byars, L.I \& Rue, L.W. (2008). Human Resource Management. $9^{\text {th }}$ ed. New York: McGraw Hill.

Chandler, A.D. Jr., (1962). Strategy and Structure: Chapters in the History of the American Industrial Enterprise. MIT Press, London, Eng. p: 105.

David, F. R. (2010). Strategic management: Concepts and cases. $12^{\text {th }}$ ed., Prentice Hall.

Early, S. (2006). Recruiting and educating a board that can add value to strategy. Strategy \& Leadership, 34(6), 54-55.

Gazzaniga, M. S. (1985). The social brain: Discovering the networks of the mind (p. 90). New York: Basic Books.

Gerhart, B., \& Milkovich, G. T. (1990). Organizational differences in managerial compensation and financial performance. Academy of Management Journal,33(4), 663-691.

Ghafarian, V., \& Ahmadi, A. (2011). Strategic thinking. Electronic Reference Management Science in Iran, 3(2), 274.

Ghafarian, V., \& Kiani, Gh. (2011). Five Command for Strategic Thinking. Publisher: Fara, $4^{\text {th }}$ ed., 75-76 [In Persian].

Goldman, E. F. (2005). Becoming an expert strategic thinker: The learning journey of healthcare CEOs (Doctoral dissertation, George Washington University.).

Goldman, E. F. (2007). Strategic thinking at the top. MIT Sloan management review, 48(4), 75.

Griffin, R., \& Moorhead, G. (2011). Organizational behavior. Cengage Learning. 
Heracleous, L. (1998). Strategic thinking or strategic planning?. Long range planning, 31(3), 481487.

Husseini Raad, M. (2011). Strategic Planning in Mashhad Municipality. $2^{\text {nd }}$ Conference on Planning and urban Management, Tabriz University.

Ja'faryani, H. (2011). Relationship between Critical Thinking and Performance. M.A. Thesis, Management and Economics Branch, Mashhad Ferdowsi University.

Kamyar, Gh. (2011). Civil Laws and Urbanization. Publisher: Majd, $4^{\text {th }}$ ed., 48.

Liedtka, J. M. (1998). Strategic thinking: can it be taught?. Long range planning, 31(1), 120-129.

Mintzberg, H. (1990). Strategy formation: Schools of thought. Perspectives on strategic management, 1968, 105-235.

Mintzberg, H. (1998). Strategy safari. New York: Free Press.

Nadler, D. A. (2004). What's the board's role in strategy development?: Engaging the board in corporate strategy. Strategy \& Leadership, 32(5), 25-33.

Rabiee, A. et al. (2011). Assessing strategic thinking levels among strategy-oriented organizations. Fifth Conference on Strategic Thinking, Payam-e-Noor University.

Rezvanpour, A. (2012). A study on managerial attitude towards the impat of employees' competence and their performance improvement in Iran department for industry of innovation and development. M.A. thesis, Tehran University of Management.

Sarhangi, R. (2011). Strategic Thinking, its Concept and improvement: Critical Review and Suggestion for future Research. fifth Conference on Strategic Thinking, Sharif Industrial University.

Shahamatnejad, M. (2012). Assessing Strategic Thinking among Tehran Municipal Managers. M.A. thesis, Tehran University of Management, p.52.

Schermerhorn Jr, J. R. (2002). Management for productivity.

O'sullivan, A. (2007). Urban economics. McGraw-Hill/Irwin.

Yazdan Panah, A.A. (2008). Up and Down in Strategy Definition (Comparative Analysis). $2^{\text {nd }}$ international Conference of Strategic Thinking, Shahid Beheshti University. 